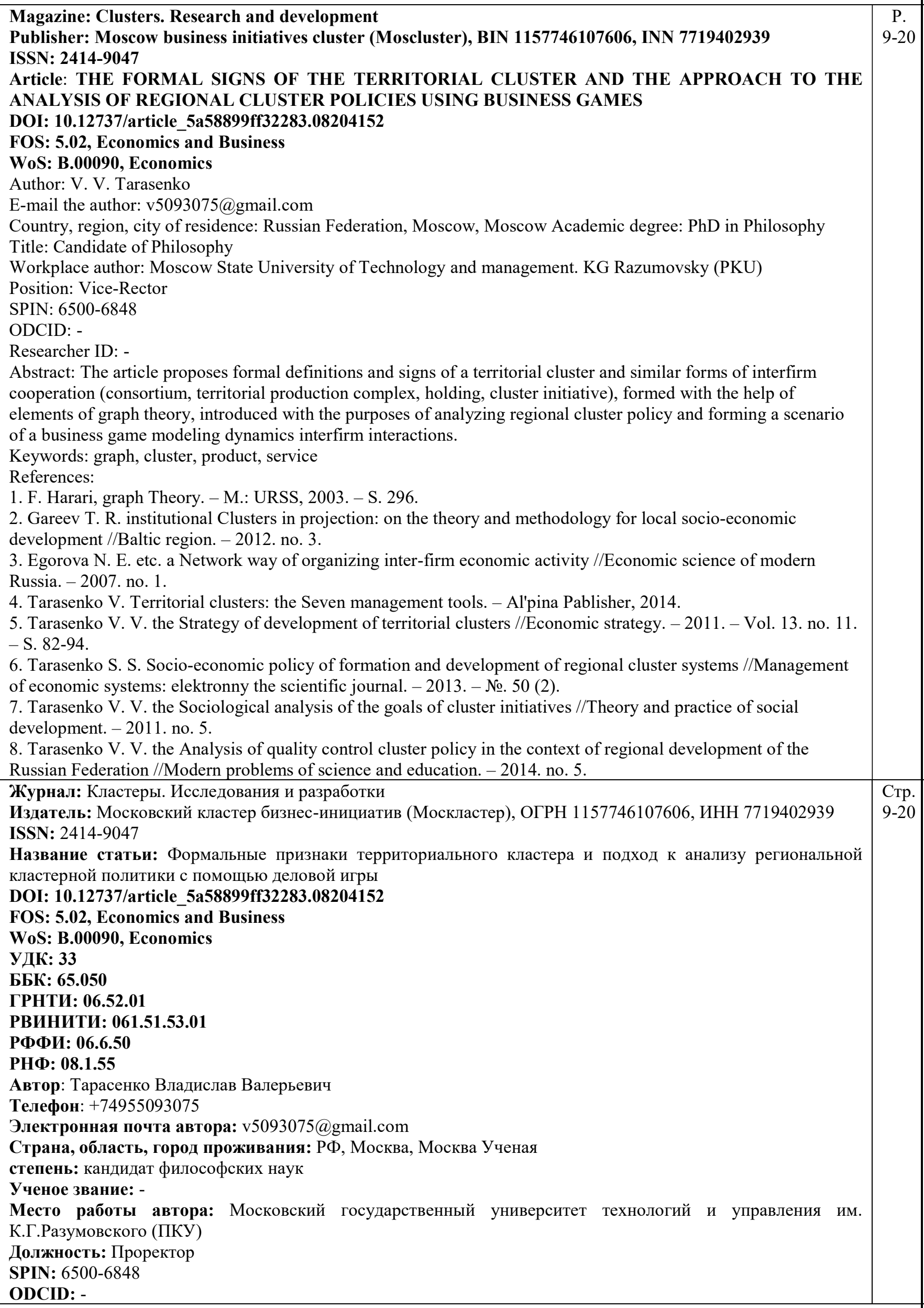




\begin{abstract}
Researcher ID:-
Аннотация: В статье предлагаются формальные определения и признаки территориального кластера и схожих форм межфирменного взаимодействия (консорциум, территориально-производственный комплекс, холдинг, кластерная инициатива), сформированные с помощью элементов теории графов, вводимые с целями анализа региональной кластерной политики и формирования сценария деловой игры, моделирующей динамику межфирменных взаимодействий.
\end{abstract}

Ключевые слова: граф, кластер, товар, услуга

Рецензия 1:

Фамилия Имя Отчество рецензента, место работы и должность, ученая степень, присвоенная или нострифицированная ВАК Минобрнауки России, зарегистрированного на сайте elibrary.ru: Ананишнев Владислав Владимирович, ООО «Москластер», Президент Кандидат экономических наук.

Степень актуальности предоставляемой статьи (соответствие содержания статьи заявленной в названии теме, соответствие современным достижениям науки, доступность читателям с точки зрения

языка, стиля, расположения материала, наглядности таблиц, диаграмм, рисунков и формул): Статья освещает проблему образования кластеров и отношений его участников по средствам экономического графа. Актуальность идей, содержащихся в рецензируемой рукописи заключается в формировании автором определённых правил и закономерностей, основанных на графическом отображении процессов развития кластерной системы. Автор успешно аргументирует свою собственную точку зрения путём подробного разбора такого понятия как мультиграф и его практического использования, а также приводит признаки региональных межфирменных взаимодействий.

Рекомендацию к публикации (в чем конкретно заключаются положительные стороны, а также недостатки статьи, какие исправления и дополнения должны быть внесены автором, целесообразность публикации статьи с учетом ранее вышедших в свет публикаций): Автор предлагает концепцию деловой игры, на основе которой происходит межфирменное взаимодействие. Особо интересным аспектом статьи является свод правил и примеры основных сценариев такого рода игры, позволяющие в полной мере представить функционирование приведённых процессов. Рекомендую статью к публикации в Фирменном научно-практическом журнале Московского кластера бизнес-инициатив (Москластер) «Кластеры. Исследования и разработки». Полагаю, что рецензируемая статья заслуживает публикации в научном издании, включенном в Перечень ВАК и РИНЦ (elibrary.ru).

\title{
Рецензия 2:
}

Фамилия Имя Отчество рецензента, место работы и должность, ученая степень, присвоенная или нострифицированная ВАК Минобрнауки России, зарегистрированного на сайте elibrary.ru: Пронин Михаил Анатольевич, Институт Философии РАН, Кандидат медицинских наук.

Степень актуальности предоставляемой статьи (соответствие содержания статьи заявленной в названии теме, соответствие современным достижениям науки, доступность читателям с точки зрения языка, стиля, расположения материала, наглядности таблиц, диаграмм, рисунков и формул): В данной статье приводится проблема нарушения работы организации, ведущий свою деятельность в системе кластерного взаимодействия. В своей работе автор осуществляет подробный анализ алгоритмов работы кластерной системы по средствам теории графов, тем самым подтверждая её актуальность. Автор успешно аргументирует свою собственную точку зрения, приводя примеры признаков региональных межфирменных взаимодействий.

Рекомендацию к публикации (в чем конкретно заключаются положительные стороны, а также недостатки статьи, какие исправления и дополнения должны быть внесены автором, целесообразность публикации статьи с учетом ранее вышедших в свет публикаций): Особенностью данной статьи является концепция деловой игры, позволяющей наладить межфирменные взаимоотношения. Автор намеренно вводит определённый свод правил в рамках концепции и подкрепляет их определёнными примерами. Рекомендую статью к публикации в Фирменном научно-практическом журнале Московского кластера бизнес-инициатив (Москластер) «Кластеры. Исследования и разработки». Полагаю, что рецензируемая статья заслуживает публикации в научном издании, включенном в Перечень ВАК и РИНЦ (elibrary.ru).

\section{Понятие экономического графа и отношений между участниками экономического графа}

Для целей нашего исследования введем понятие экономического графа в виде социально-экономических отношений между фирмами, а так же 
организациями, частными предпринимателями и частными инвесторами (далее участниками), которые можно описать в виде ориентированного мультиграфа

$$
G=\langle\mathrm{P}, A\rangle,
$$

множество вершин которого $P$ соответствует множеству участников, а множество дуг (или ребер) $A$ которого соответствует множеству социально-экономических отношений между множеством участников $P$.

Как известно из теории графов, мультиграф отличается от графа допустимостью нескольких кратных (параллельных) дуг между двумя вершинами. Ориентированный граф отличается от обычного графа тем, что все его дуги упорядочены - имеют начальные и конечные вершины. Стрелка на дуге указывает на конечную вершину дуги. Кроме того, для целей нашего исследования мы допускаем существование гиперребер - неупорядоченных непустых подмножеств множества Р с числом элементов от 2 до числа, равному числу вершин мультиграфа.

Определим четыре вида социально-экономических отношений между участниками экономического графа $G$, которые определяются характеристиками его вершин, дуг и гиперребер и которые далее будут определять понятие и формальные признаки территориального кластера:

отношения купли-продажи товаров, услуг, работ;

отношения собственности либо выгодообладания;

отношение принадлежности участника к территории (региону);

отношения совместной деятельности (проекта, программы) двух и более участников.

Отношения купли-продажи товаров, услуг, работ определим через подмножество множества $A$, структурированное по видам экономической деятельности.

Пусть участник $p_{1} \in P$ (продавец) продает участнику $p_{2} \in P$ (покупателю) $n$ товаров или работ или услуг, в течение определенного срока, которые характеризуются множеством из $n$ подмножеств $R_{1}^{12}, R_{2}^{12} \ldots R_{n}^{12}$. Допустим, что участник $p_{2} є P$ тоже может быть в роли продавца и продавать покупателю участнику $p_{1} \in P k$ товаров или работ или услуг, в течение определенного срока которые характеризуются множеством из $k$ подмножеств $R_{1}^{21}, R_{2}^{21} \ldots . R_{k}^{21}$. Очевидно, что множества $R^{12}$ и $R^{21}$ должны быть подмножествами множества $A$.

В подмножество $R_{i}$ можно включать:

объем продаж $i$-го товара (услуги, работы) за определенный срок;

среднюю цену товара (услуги, работу) по которой продавался (покупался) товар за определенный срок;

код товара (услуги, работы) по которому продавался (покупался), товар; виды экономической деятельности, необходимые для производства товара (услуги) и прочие качественные и количественные характеристики.

Определим, также то, что если объем продаж $i$-го товара (услуги, работы) за определенный срок является нулевым, то все остальные элементы подмножества $R_{i}$ являются нулевыми, а множество является пустым. 
Определим отношения купли-продажи между двумя участниками как непустое объединение множеств $R^{12}$ и $R^{21}$.

Графически это определение представлено на рисунке ниже, при этом стрелки показывают упорядоченность дуг мультиграфа $C$, которое можно интерпретировать как движение товаров, или работ или услуг по направлению от участника-продавца (начальная вершина) к покупателю (конечная вершина).

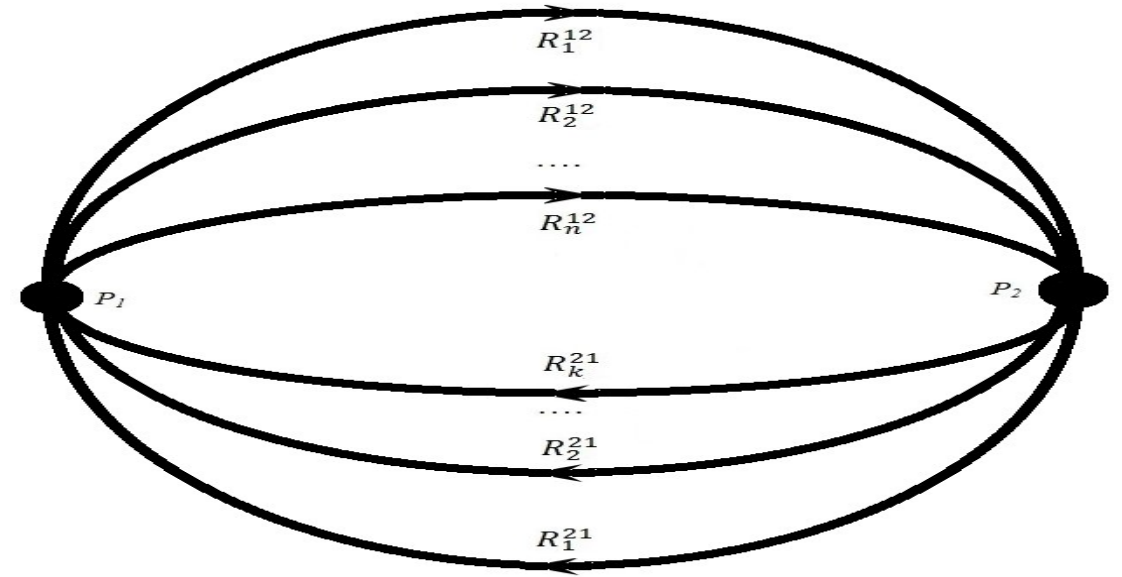

Отношения купли-продажи между двумя участниками $p_{1}$ и $p_{2}$

Частными случаями отношений купли-продажи можно считать отношения только купли или только продажи - относительно одного из контрагентов. В этом случае $p_{1}$ и $p_{2}$ не могут быть одновременно в двух ролях - продавца и покупателя, то есть одно из множеств $R^{12}$ и $R^{21}$ должно быть нулевым.

Предположим, что различия между территориальным кластером (ТК) и территориально-производственным комплексом (ТПК) состоит в большей зависимости участников ТПК друг от друга, чем у участников ТК. Это связано с тем, что в ТПК покупатели и поставщики структурированы в жесткую цепочку поставок товаров и услуг, а ТK предполагает конкуренцию между специализированными поставщиками.

Это отличие можно зафиксировать по структуре закупок и продаж. Определим, что если более $80 \%$ объема всех продаж у более $80 \%$ участников приходится на единственного покупателя либо более $80 \%$ объема закупок у более $80 \%$ участников приходится на единственного поставщика, то можно говорить о том, что экономический граф относится к ТПК.

Если закупки и продажи диверсифицированы в большей степени, то мы будем говорить о кластерной форме организации экономического графа.

Частным случаем отношений купли-продажи являются иерархические отношения, связанные со специализацией участников кластера либо ТПК, которые проявляются в развитии и усложнении уровней экономической деятельности, проявляющихся при отказе участников от диверсификации своих бизнесов.

Классическая цепочка ценностей подразумевает следующие переделы, подразумевающие разделение видов деятельности по следующим уровнями:

добыча и первичная переработка сырья;

изготовление полуфабрикатов и заготовок; 
изготовление деталей машин и инструментов;

изготовление узлов, агрегатов и подсистем;

изготовление средств производства (оснастка, станки, расходные материалы);

изготовление и продажа конечной продукции.

Помимо этого, в цепочку ценности могут включаться обеспечивающие процессы, связанные с финансовой деятельностью, обучением, маркетингом и продажами.

Количество и сложность уровней экономической деятельности, связанных с переделами может варьироваться в зависимости от отраслевой специфики.

Будем называть глубиной структуры видов экономической деятельности участников количество уровней деятельности, характерных для региональной цепочки ценности.

Будем называть шириной структуры видов экономической деятельности количество видов деятельности на уровне.

Предположим, что успешная кластерная политика подразумевает увеличение сложности структуры видов деятельности в виде увеличения глубины и ширины структуры видов экономической деятельности участников региональных экономических взаимодействий.

Отношения собственности (выгодообладания) так же определим через подмножество множества $A$ как обладание участником $p_{I} \in P$ (собственник либо выгодоприобретатель) правом собственности на фирму либо правом получения выгод от деятельности организации участника $p_{2} \in P$ (собственность) с количественной характеристикой $O_{12}$, а участник $p_{2} \in P$ (собственник либо выгодоприобретатель) обладает правом собственности на фирму либо правом получения выгод от деятельности организации участника $p_{I} \in P$ (собственность) с характеристикой $O_{21}$.

Графически это определение представлено на рисунке ниже, при этом стрелки показывают упорядоченность дуг мультиграфа $C$, которое можно интерпретировать следующим образом: $p_{1}$ владеет собственностью $p_{2}$ в размере $O_{12}$, а $p_{2}$ владеет собственностью $p_{1}$ в размере $O_{21}$.

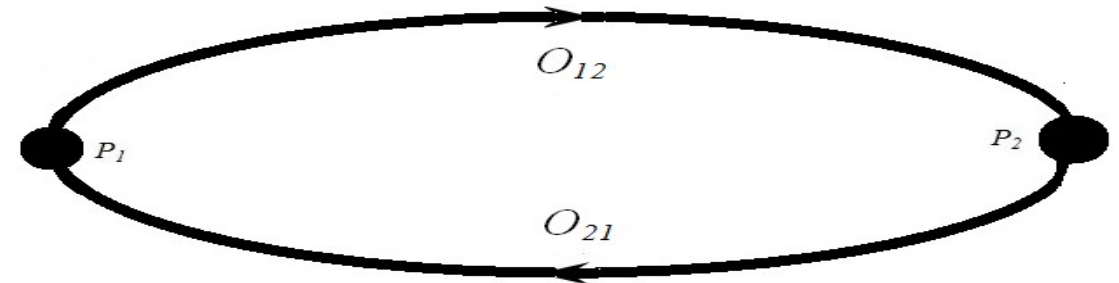

Отношения собственности между двумя участниками $p_{1}$ и $p_{2}$

Назовем участника $P_{i}$ основным собственником (основным выгодополучателем) участника $P_{k}$, если он владеет более $50 \%$ его собственности, 
либо имеет право на получение более $50 \%$ выгод от деятельности участника $P_{k}$ в денежном эквиваленте за определенный срок.

Анализ отношений собственности необходим нам для различения ТК и холдинга. Определим, что если более $50 \%$ участников экономического графа принадлежит непосредственно либо опосредованно одному основному собственнику, то такой граф является холдинговой структурой и не является ТК.

Отношение территориальной принадлежности определим, как принадлежность множества $P$ участников множеству фирм, организаций, частных предпринимателей и частных инвесторов $T$, расположенных на заранее определенной территории (например, на территории одного субъекта Российской Федерации), которую мы будем называть территорией локализации социальноэкономических отношений:

$$
P \subseteq T
$$

Схематически будем обозначать территориальную принадлежность в виде гиперребра $T$ - неупорядоченного подмножества участников, принадлежащих множеству $T$.

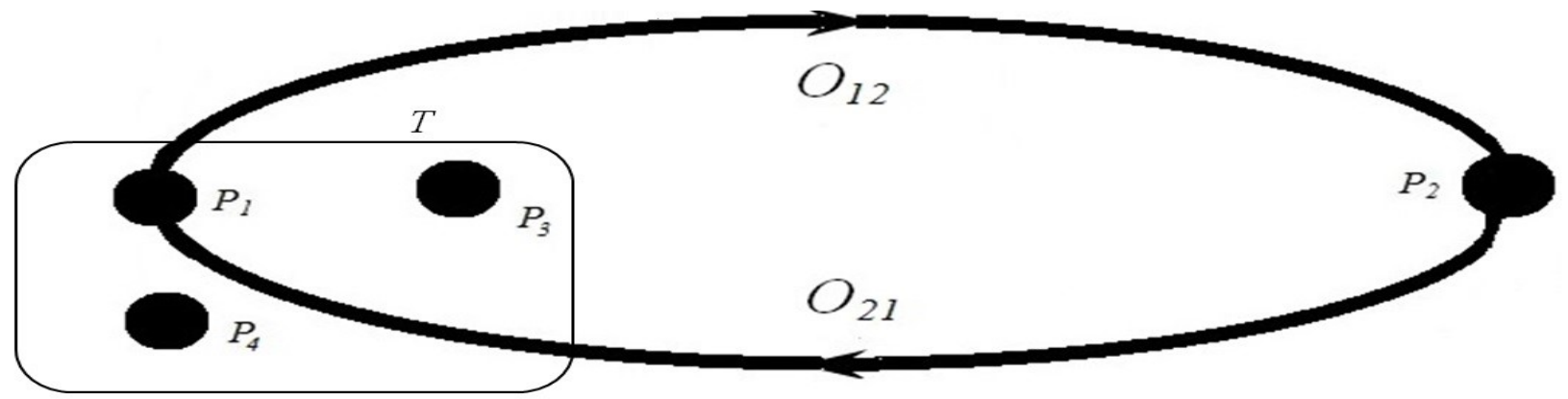

Отношения купли-продажи между двумя участниками $p_{1}, p_{3}$ и $p_{4}$

Определим, что необходимым условием определения экономического графа как кластера, кластерной инициативы либо как ТПК является принадлежность не менее $80 \%$ участников заранее определенному территориальному множеству T.

Отношения совместной деятельности (проекта, программы) двух и более участников экономического графа определим как гиперребро $P J$ графа $\mathrm{C}$, из $k$ вершин, характеристикой которого является количественная оценка финансовых и нефинансовых ресурсов $I_{1}, I_{2}, \ldots I_{k}$ проинвестированных в течение определенного времени в совместную деятельность (проект) каждого из $k$ участников, которая зафиксирована в соглашении о совместной деятельности, либо в договоре, регламентирующим работы в совместном проекте. Пример совместного проекта трех участников дан на рисунке. 


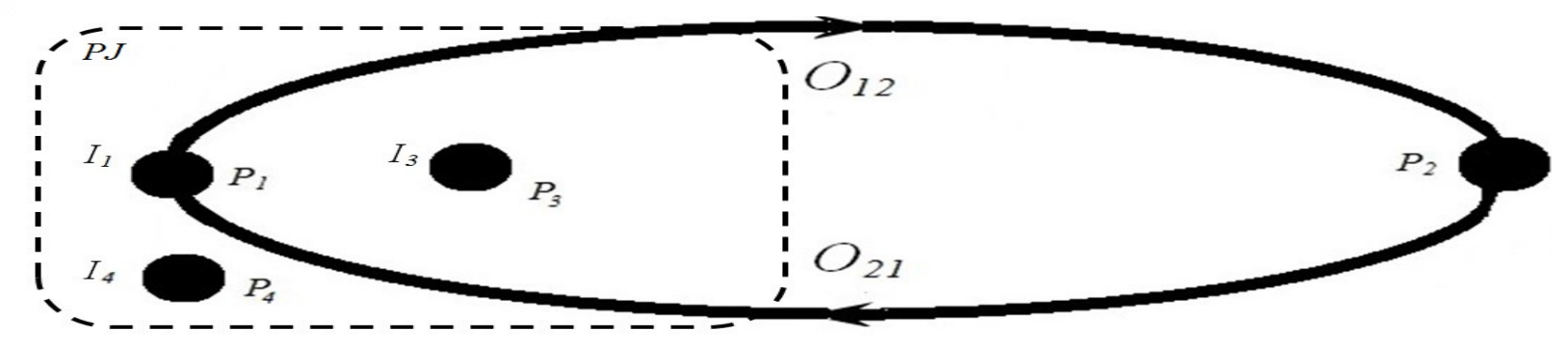

Отношения совместной деятельности между двумя участниками $p_{1}, p_{3}$ и $p_{4}$

Определим, что отношения совместной деятельности между участниками характерно для консорциума, кластерной инициативы и территориального кластера.

Определения консоричима, холдинга, кластерной иницуиативы, территориально-производственного комплекса, территориального кластера как частных случаев экономического графа

Обозначим необходимость обсуждаемых ранее признаков в определении консорциума, территориально-производственного комплекса, холдинга, кластерной инициативы и территориального кластера единицей, а необходимость их отсутствия нулем. Пустая клетка будет означать отсутствие требований присутствия или отсутствия признака в определении.

Отсутствие признака может так же демонстрировать возможность пересечения понятий. Например, ТПК может быть одновременно холдингом и входить в консорциум.

Сведем признаки в общую таблицу определения понятий:

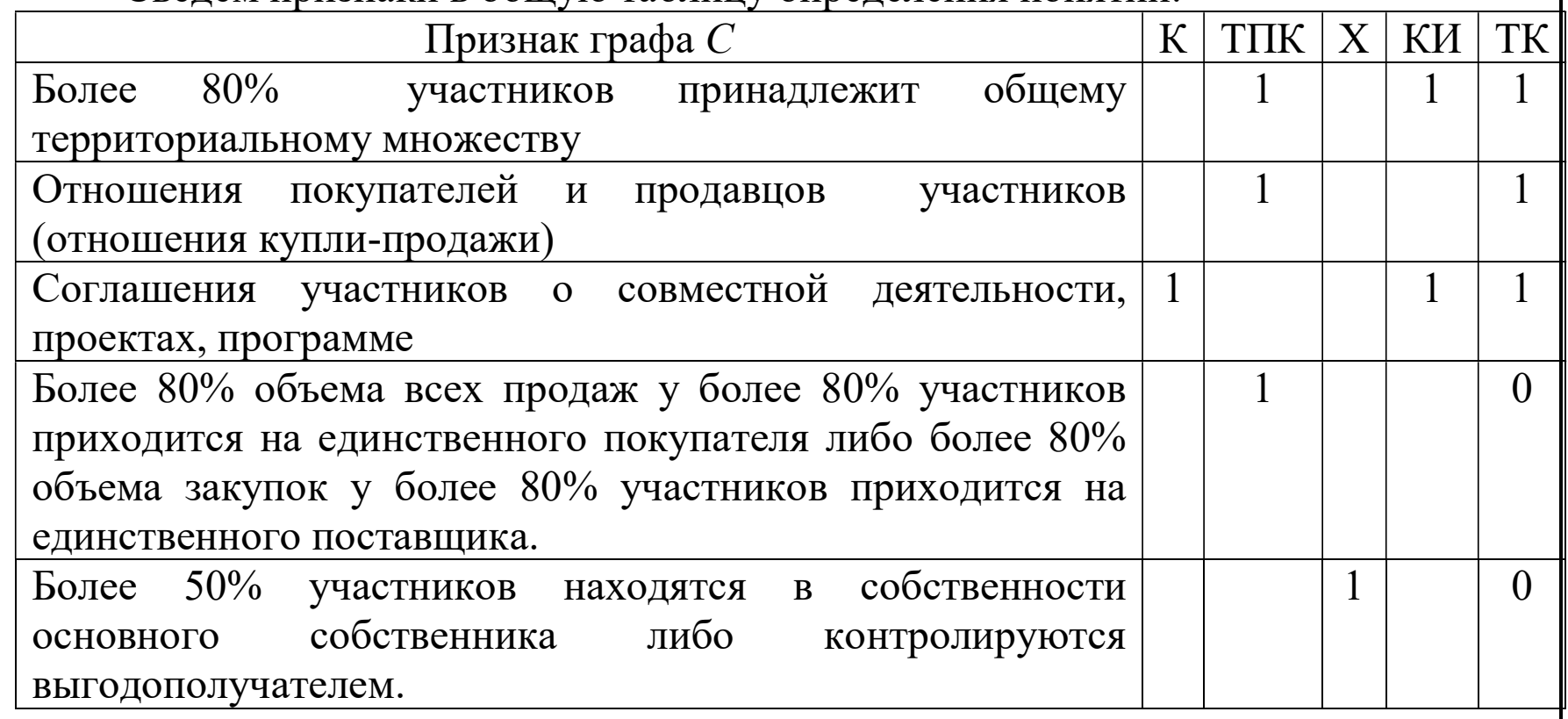

где:

К - консорциум,

ТПК - территориально-производственный комплекс,

$\mathrm{X}$ - холдинг, 
КИ - кластерная инициатива,

ТК - территориальный кластер.

Данная таблица устанавливает с одной стороны сходства и различия понятий, описывающих частные случаи экономических отношений в экономическом графе, a c другой стороны определяет необходимые и достаточные условия территориального кластера.

Конџепџия деловой игры на базе формальных критериев межфирменных взаимодействий

Описанные выше признаки региональных межфирменных взаимодействий можно применить с одной стороны для статистической и экспертной оценки реализации кластерной политики региона, а с другой стороны - для подготовки региональных команд развития и тренировки навыков принятия управленческих решений, направленных на реализацию эффективной кластерной политики и отработку стратегий межфирменного взаимодействия в деловой игре.

В качестве примера дадим основные правила и сценарии такого рода деловой игры.

Каждый игрок владеет несколькими участниками - организациями, осуществляющими несколько видов экономической деятельности. Все виды экономической деятельности распределены по уровням структуры экономической деятельности - от добычи сырья до продаж конечной продукции кластера или ТПК.

Игра моделирует стратегии и решения участников, связанные как с увеличением, так и уменьшением видов экономической деятельности, формированием кластерных взаимодействий, либо взаимодействий в рамках развития ТПК.

В частности, моделируются следующие решения между участниками региональных экономических отношений:

закупка товаров (услуг) у участников, обладающих более низким уровнем экономической деятельности;

передача (аутсорсинг-инсорсинг) деятельности от участника участнику, включая оптимизацию видов деятельности холдинга и формирование кластерных взаимодействий;

купля-продажа (слияние-поглощение) участника (передача-получение всех видов деятельности);

создание участника (получение видов деятельности новым участником).

Параметры игры:

И - количество игроков $(И=8)$. Не меняется в игре.

УИ - распределение участников графа $C$ между игроками. В начале игры для каждого участника УИ=2. Далее УИ может меняться в результате решений участников. 
ОУ - общее количество участников графа $C$. На начальном шаге ОУ=УИ* Далее ОУ может меняться в результате решений участников.

Для каждого участника на каждом шаге фиксируется остаток средств в игровой валюте - уе. и остатки объемов в товарных единицах по каждому виду деятельности.

ОЭД - общее количество видов экономической деятельности, структурированных по У уровням экономической деятельности. ОЭД $=12$. ОЭД постоянно во время игры.

ЭДУ(К) - начальное количество видов экономической деятельности у участника.

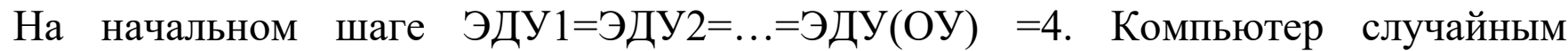
образом задает каждому участнику ЭДУ видов деятельности из ОЭД видов деятельности, специфицируя каждому участнику объемы товарных единиц по каждому виду деятельности. При этому виды ЭДУ может меняться в процессе игры в результате решений участников.

У - глубина структуры экономической деятельности в виде количества уровней структуры экономической деятельности участников региональных экономических взаимодействий - переделов в цепочке кластера или ТПК от добычи сырья до продажи конечного продукта.

$\mathrm{У}=4$. У постоянно во время игры

У одного участника могут быть виды деятельности разных уровней. По правилам игры участники могут закупать товары и услуги только у участников, обладающих видами деятельности более низкого уровня.

Каждый вид деятельности обладает следующими характеристиками:

ОД - объем деятельности (в товарных единицах - т.е.);

КВ - конверсия в виде коэффициента преобразования объема деятельности нижнего уровня в объем деятельности верхнего уровня. Например, КВ34=5 означает, что для выпуска одной товарной единицы четвертого уровня необходимо пять товарных единиц третьего уровня;

ПЗ - постоянные затраты (фиксированная величина в уе на одного участника с одним видом деятельности);

ПП - переменные затраты (в у.е. на единицу товара).

На каждом шаге ведущий игры меняет:

Объем продаж и объем деятельности участников, обладающими деятельностью верхнего уровня (сборкой конечного продукта и продажами продукции кластера).

Так же ведущий может изменить нормативы постоянных и переменных затрат для каждого уровня.

Игра осуществляется по шагам (периодам).

В начале периода ведущий задает объем закупок кластера (с высшего уровня) и перечисляет деньги, равные общему объему закупок участникам, обладающим высшими уровнями деятельности (сборкой конечного продукта и продажами продукции кластера) по формуле:

$$
\mathrm{O} 3 \mathrm{Y}=\mathrm{OY} * \mathrm{O} 3 \mathrm{~K} / \mathrm{OO} \text {, }
$$


Где ОЗУ - объем закупок у участника,

ОЗК - объем закупок у кластера;

ОУ - объем деятельности у участника;

ОО - общий объем деятельности.

После этого ведущий открывает этап контрактации, на котором участники принимают решения об объеме закупок у участников, имеющих нижестоящие уровни деятельности в текущем периоде.

В частности, участники, обладающие высшим (четвертым) уровнем деятельности принимают решения об объеме закупок товаров и услуг у участников, обладающих третьим уровнем деятельности и перечисляют им деньги на закупку товаров и услуг, ориентируясь конверсию, объем поступления денег от ведущего и свои ожидания по поступлениям денег от будущих периодов.

Далее участники с третьим уровнем деятельности объявляют объемы закупок участникам второго уровня деятельности. Участники, обладающие видами деятельности второго уровня, доводят объемы закупок до первого уровня деятельности, а первый уровень деятельности закупает товары и услуги вне кластера.

После этого ведущий объявляет этап субконтрактации и участники совершают сделки по аусорсингу-инсорсингу, купле-продаже бизнесов и созданию участников.

При передаче видов деятельности на аутсорсинг и принятии вида деятельности меняется формула расчета постоянных и переменных затрат предприятия.

После закрытия закупок и сделок, участники подсчитывают прибыль (убытки) периода, суммируют их с прибылью (убытками) предыдущих периодов и переходят на следующий шаг.

После осуществления определенного количества шагов ведущий организует обсуждение анализа игровой динамики региональной кластерной политики.

\section{Анализ динамики региональной кластерной политики}

Предложенные нами определения и деловая игра необходимы для того, чтобы управленцы смогли оценить качественную динамику реализации промышленной политики региона. Указанная политика подразумевает, в том числе, наличие целей, связанных с формированием необходимых межфирменных отношений и реализацией кластерной политики.

Чаще всего цели кластерной политики связаны с локализацией в территориальных кластерах новых участников межфирменных взаимодействий, увеличением качества и глубины межфирменной кооперации, развитие совместных проектов, развитие конкуренции и уменьшение взаимной зависимости участников межфирменных взаимодействий, переход от вертикально-интегрированных холдингов к кластерным формам взаимодействия.

Структурируем формальные критерии реализации кластерной политики региона в таблице. 


\begin{tabular}{|c|c|c|c|}
\hline $\begin{array}{c}\text { Показатель } \\
\text { кластерной } \\
\text { политики региона }\end{array}$ & $\begin{array}{c}\text { Формальные критерии } \\
\text { положительной } \\
\text { динамики кластерной } \\
\text { политики региона }\end{array}$ & $\begin{array}{c}\text { Нейтральная } \\
\text { динамика }\end{array}$ & $\begin{array}{c}\text { Формальные } \\
\text { критерии } \\
\text { отрицательной } \\
\text { динамики кластерной } \\
\text { политики региона } \\
\end{array}$ \\
\hline $\begin{array}{l}\text { Локализация } \\
\text { участников } \\
\text { территории }\end{array}$ & $\begin{array}{c}\text { Увеличение числа } \\
\text { участников графа } C \text {, } \\
\text { принадлежащих } T\end{array}$ & $\begin{array}{c}\text { Без } \\
\text { изменений }\end{array}$ & $\begin{array}{c}\text { Увеличение числа } \\
\text { участников графа } C \text {, } \\
\text { принадлежащих } T\end{array}$ \\
\hline $\begin{array}{l}\text { Изменение } \\
\text { отношений купли- } \\
\text { продажи } \\
\text { участников }\end{array}$ & $\begin{array}{c}\text { Увеличение } \\
\text { элементов множества } \\
R\end{array}$ & $\begin{array}{c}\text { Без } \\
\text { изменений }\end{array}$ & $\begin{array}{c}\text { Уменьшение } \\
\text { элементов множества } \\
R\end{array}$ \\
\hline $\begin{array}{l}\text { Изменение } \\
\text { совместной } \\
\text { деятельности } \\
\text { (проектов) } \\
\text { участников } \\
\end{array}$ & $\begin{array}{c}\text { Увеличение числа } \\
\text { гиперребер } P J \text { графа } \\
C\end{array}$ & $\begin{array}{c}\text { Без } \\
\text { изменений }\end{array}$ & $\begin{array}{c}\text { Уменьшение числа } \\
\text { гиперребер } P J \text { графа } \\
C\end{array}$ \\
\hline $\begin{array}{l}\text { Изменение } \\
\text { конкуренции и } \\
\text { взаимной } \\
\text { зависимости } \\
\text { участников }\end{array}$ & $\begin{array}{c}\text { Уменьшение доли } \\
\text { закупок у } \\
\text { единственных } \\
\text { продавцов у } \\
\text { участников либо } \\
\text { поставок } \\
\text { единственному } \\
\text { покупателю }\end{array}$ & $\begin{array}{c}\text { Без } \\
\text { изменений }\end{array}$ & $\begin{array}{c}\text { Увеличение доли } \\
\text { закупок у } \\
\text { единственных } \\
\text { продавцов у } \\
\text { участников либо } \\
\text { поставок } \\
\text { единственному } \\
\text { покупателю }\end{array}$ \\
\hline $\begin{array}{l}\text { Изменение числа } \\
\text { собственников } \\
\text { предприятий }\end{array}$ & $\begin{array}{c}\text { Увеличение числа } \\
\text { собственников } \\
\text { участников графа } C\end{array}$ & $\begin{array}{c}\text { Без } \\
\text { изменений }\end{array}$ & $\begin{array}{c}\text { Уменьшение числа } \\
\text { собственников } \\
\text { участников графа } C\end{array}$ \\
\hline $\begin{array}{l}\text { Изменение } \\
\text { глубины } \\
\text { структуры видов } \\
\text { экономической } \\
\text { деятельности }\end{array}$ & $\begin{array}{c}\text { Увеличение уровней } \\
\text { структуры видов } \\
\text { экономической } \\
\text { деятельности } \\
\text { участников графа } C\end{array}$ & $\begin{array}{c}\text { Без } \\
\text { изменений }\end{array}$ & $\begin{array}{c}\text { Уменьшение уровней } \\
\text { структуры видов } \\
\text { экономической } \\
\text { деятельности } \\
\text { участников графа } C\end{array}$ \\
\hline
\end{tabular}

По этим параметрам можно оценивать с одной стороны результаты игра, а с другой - реализацию кластерной политики региона.

\section{Список литературы}

1. Харари Ф. Теория графов. - М. : УРСС, 2003. - С. 296.

2. Гареев Т. Р. Кластеры в институциональной проекции: к теории и методологии локального социально-экономического развития //Балтийский регион. - 2012. - №. 3 . 
3. Егорова Н. Е. и др. Сетевой способ организации межфирменной экономической деятельности //Экономическая наука современной России. - 2007. №. 1.

4. Тарасенко В. Территориальные кластеры: Семь инструментов управления. Альпина Паблишер, 2014.

5. Тарасенко В. В. Стратегии развития территориальных кластеров //Экономические стратегии. - 2011. - Т. 13. - №. 11. - С. 82-94.

6. Тарасенко С. С. Социально-экономическая политика формирования и развития региональных кластерных систем //Управление экономическими системами: электроннный научный журнал. - 2013. - №. 50 (2).

7. Тарасенко В. В. Социологический анализ целей кластерных инициатив //Теория и практика общественного развития. -2011 . - №. 5.

8. Тарасенко В. В. Анализ качества управления кластерной политикой в контексте регионального развития Российской Федерации //Современные проблемы науки и образования. - 2014. - №. 5. 